\title{
Brakial Pleksus Bloğunun Pletismografik Variabilite İndeksi ve Perfüzyon Indeksi ile Değerlendirilmesi
}

Evaluation of Brachial Plexus Block With Plethysmographic Variability Index and Perfusion Index

\author{
Enes ÇELIK ${ }^{1}{ }^{(D)}$, Gönül ÖLMEZ KAVAK²
}

${ }^{1}$ TC Sağlık Bakanlığı Mardin II Sağlık Müdürlüğü Derik Devlet Hastanesi , Mardin, TÜRKiYE

2 Dicle Üniversitesi Tıp Fakültesi Hastanesi, Anesteziyoloji ve Reanimasyon Anabilimdalı, Diyarbakır, TÜRKiYE

Öz.

Amaç: Blok başarısının değerlendirilmesi için kullanılan geleneksel yöntemler zaman alıııdır ve hasta kooperasyonuna intiyaç duyar. Bu çalışmanın amacı; Perfüzyon Indeksi ve Pletismografik Variabilite Indeksinin brakiyal sinir blokajının başarısını tahmin etmek için kullanılıp kullanılamayacağını değerlendirmektir.

Materyal ve metod: Bu çalışmaya $18-65$ yaş arası, elektif veya acil cerrahi operasyona alınan 34 hasta dahil edildi. Brakialpleksus bloğu uygulandı. Kardiyak hastalığı, kronik obstrüktif akciğer hastalığı ve astım hastalığı olanlar çalışma dışı bırakıldı. Hastaların yatak başı, noninvaziv, seri pletismografik variabilite indeksi (PVI) ve perfüzyon indeksi (PI) ölçümleri, blok uygulanan elin dördüncü parmak ucundan Radical-97 PulseOksimetre cihazı kullanılarak yapıldı.

Bulgular: Blok yapılan koldan ölçülen PVI değerleri karşılaștıııldığında; 0 ile 5. dk, 5. dk ile 10. dk ve 0 ile 10.dk arasındaki farklılık istatistiksel olarak anlamlı bulundu. PI değerleri 0 ve $5 . \mathrm{dk}, 5$ ve $10 . \mathrm{dk}$, 0 ve $10 . \mathrm{dk}$ olarak karşılaştırıldı̆̆ında değişimler istatistiksel olarak anlamlı bulundu.

$(p<0.05)$

Sonuç: Çalışmamızda PI ve PVI değerindeki değişimlerin istatistiksel olarak anlamlı olduğu görüldü. ( $p<0.05)$ $\mathrm{PVI}$ ve PI arasında istatistiksel olarak anlamlı korelasyon saptanmadı.

Anahtar Kelimeler: Anestezi, Brakial Pleksus Blok, Hemodinamik Takip

Abstract

Background: Conventional methods for evaluation of block success are time consuming and need patient cooperation. The aim of this study was to evaluate whether the Perfusion Index and Plethysmographic Variability Index can be used to predict brachial nevre block success.

Materials and Methods: Thirty-four patients, aged 18-65 years, who were transferred to elective or emergency surgery were included. Brachial plexus block was applied. Those with cardiac disease, chronic obstructive pulmonary disease and asthma were excluded from the study. Bedside, non-invasive, serial plethysmographic variability index (PVI) and perfusion index (PI) measurements of the patients were made using the Radical-97 Pulse Oximeter device from the fourth finger tip of the blocked hand.

Results: When the PVI values measured from the blocked arm were compared; The difference between 0 and 5 minutes, 5th and 10th minutes and 0 to 10 minutes was statistically significant. When PI values were compared as 0 and 5 minutes, 5 and 10 minutes, 0 and 10 minutes, the changes were statistically significant. ( $p<0.05)$.

Conclusion: In our study, it was seen that the changes in PI and PVI values were statistically significant. $(p<0.05)$ There was no statistically significant correlation between PVI and PI.

Key Words: Anaesthesia, Brachial Plexus Block, Hemodynamic Monitoring
Sorumlu Yazar/Corresponding Author

Dr. Enes ÇELIK

TC Sağılık Bakanlığı, Mardin III Sağlık Müdürlüğü Derik Devlet Hastanesi Zeytinpınar Mahallesi, Roj Caddesi, Külebe Mevkii No: 19, Derik/Mardin/TÜRKiYE

E-mail: anestezistenescelik@gmail.com

Geliş tarihi / Received: 17.03.2021

Kabul tarihi / Accepted: 08.07.2021

DOI: $10.35440 /$ hutfd. 896408

Bu çalışma Tıpta Uzmanlık Tezinden türetilmiştir. YÖK Tez Merkezi Referans No:10358110 


\section{Giriş}

Son yıllarda tıbbın her alanında olduğu gibi anestezi alanında da hemodinamik monitorizasyon sıklıkla kullanılmaktadır.

Perfüzyon indeksi (PI), kapiller yataktaki nonpulsatil akımın pulsatil akıma oranıdır. PI vazomotor tonusu yansıtır ve bu sayede noninvaziv ve sürekli olarak pulse oksimetre aracılı periferik perfüzyon takibi sağlanır. Massimo Pulse oksimetre cihazı 0.02 den 20'ye kadar değerler verir. Normal ortalama değeri 1.4 tür.

Perfüzyon indeksi ölçümü, primer olarak monitorize edilen alandaki kan miktarından etkilenir ve bu ölçüm kalp hızı, oksijen saturasyonu, oksijen tüketimi, sıcaklık gibi fizyolojik değişimlerden bağımsızdır. Sistemik veya bakıldığı yerdeki lokal sebeplere bağlı oluşan vazokonstriksiyon PI' de azalmaya, vazodilatasyon ise $\mathrm{PI}^{\prime}$ de artışa neden olur.

Pleth variabilite indeksi (PVI), yüzde olarak gösterilir. Değer azaldıkça, respiratuvar sikluslardaki PI' de daha az variabilite olduğu anlamına gelmektedir. PI değişimleri çeşitli nedenlere bağlıdır. Epidural bloklar, ağrı uyarımları, sempatik deşarjlar ve azalan periferik perfüzyon gibi faktörlerden etkilenir(1).

Perfüzyon indeksi, sempatik blokajı göstermede cilt sıcaklığı artışı ve motor-duyusal fonksiyonun azalmasından daha erken belirteçtir. Brakial pleksus blokları sonrasında oluşan sempatik blokaj ve vazodilatasyona bağlı artan kan akımını göstermede de kullanışlı bir belirteçtir

Pleth variabilite indeksi, sıvı durumunu ve sıvıya yanıtlılığını yansıtır. Pleth variabilite indeksi monitörizasyonu ile intraoperatif hipotansiyon ve sıvı ihtiyacının önceden tahmin edilebildiği de gösterilmiştir(2).

Pleth variabilite indeksi ve PI ile yapılan çalışmaların çoğunda bu belirteçler intratorasik basınç ve solunum döngüsünden etkilendiği için mekanik ventilatöre bağlı hastalarda yapılmıştır. Ama yapılan son çalışmalar, daha fazla çalışmaya ihtiyaç olduğuna vurgu yaparak spontan solunumu olan hastalarda da bu indekslerin kullanılabileceğini ortaya koymuştur (3-5).

Pletismografik Variabilite İndeksi ölçümü için eşik değer \%14 olarak kabul edilmektedir. Bu değerden yüksek değerlerde hastaya uygulanan iv sıvı replasmanından hasta fayda görmekte ve hacim genişlemesi sağlanabilmektedir (6). PVI değeri genel anestezi altında, övolemik hastalarda 10-12'den az, uyanık hastalarda ise 18-25 arasında beklenir (5).

Bu çalışmada; Üniversitesimiz Hastaneleri ameliyathanelerinde elektif veya acil cerrahi operasyona alınan ve brakial pleksus bloğu uygulanan hastalarda yatak başı Radical97TM Pulse CO-Oksimetre ${ }^{\circledR}$ (MasimoCorp, Irvine, CA, ABD) (noninvaziv) PVI ve PI değerleri ile blok başarısının sayısal değerlerle objektif olarak değerlendirilmesi amaçlandı. Ayrıca elde edilen PI ve PVI değerleri arasında korelasyon olup-olmadığı araştırıldı.

\section{Materyal ve Metod}

Çalışma öncesi Dicle Üniversitesi Tıp Fakültesi Girişimsel Olmayan Klinik Araştırmalar Etik Kurulundan onay alındı. (Onam no: 07 , Onam tarihi: 14.11.2019) Çalışma prospektif olarak planlandı. Katılımcılar, çalışma öncesinde, çalışma ile ilgili tüm detaylar hakkında hem sözel hem de yazılı olarak bilgilendirildi. Ardından katılımcılardan aydınlatılmış onam alındı.

$\mathrm{Bu}$ çalışmaya acil veya elektif operasyonu planlanan, üst ekstremitesinden opere olacak olan hastalardan kanama diatezi olmayan, işlem yerinde enfeksiyon olmayan ve ASA I-III fiziksel skorlarına sahip hastalar tercih edildi. Kardiyak hastalığı - KOAH - astım hastalığı olmayan, 18-65 yaş arasındaki, üst ekstremitesine ileti bloğu uygulanmış olan otuz dört hasta dahil edildi. Çalışmamıza rejyonal anestezi için iletişim kurulamayan hastalar dahil edilmedi. Bloğun başarısız olduğu hastalar çalışma dışı bırakıldı. Çalışma için herhangi bir invaziv işlem uygulanmadı. Zaten brakial pleksus bloğu çalışmadan bağımsız olarak uygulanacak olan hastalar seçildi.

Hastalar, işlem yapılacak olan ameliyathaneye alınarak elektrokardiyografi (EKG), noninvaziv arteriyal kan basıncı ve pulse oksimetreyi $\left(\mathrm{SpO}_{2}\right)$ içerecek şekilde rutin monitorizasyonları yapıldı. Hastalara, işlem yapılmayacak olan kolda, 18 veya 20 gauge kanül ile periferik iv damaryolu açıldı. Blok işlemi uygulanmadan önce hastaların damar yolu kontrol edildi. Ve 10. dk ölçümü alınana kadar iv sıvı replasmanı yapılmadı.

Hastaların PVI, PI, $\mathrm{SpO}_{2}$, SpHbg ölçümleri, opere olan elin uygunsa dördüncü parmak ucundan kaydedildi.

Hastaların tamamına aynı anestezist tarafından ultrason ve sinir stimülatörü eşliğinde brakial pleksus blokları uygulandı. Cerrahi bölgeye göre aksiller, infraklavikular veya supraklavikular blok uygulandı. Tüm ölçümler ve muayene bulguları ise ayrı bir anestezist tarafından yapılıp, kaydedildi. Ultrason in-plane teknikle kullanıldı. Olası komplikasyonlar açısından anestezi masasında genel anestezi şartları hazır bulunduruldu. İşleme başlamadan önce bazal değerlerin ölçümü yapıldı.

Blok için kullanılacak olan stimülasyon iğnesi eşzamanlı olarak sinir stimülatörüne (Stimuplex HNS 12, BraunMedical, Melsungen, Germany) bağlandı. Blok iğnesi sinir stimülatörüne bağlanarak başlangıç atımı 1,0miliamper(mA) olarak ayarlandı. Stimülatörde 0,5 mA akım altında uyarı alındıktan sonra negatif aspirasyon testinin ardından hazırlanan karışım enjekte edildi. Aksiller ve infraklavikular blok için $1,5 \mathrm{mg} / \mathrm{kg}$ bupivakain ve $3 \mathrm{mg} / \mathrm{kg}$ lidokain karışımı kullanıldı. Supraklavikular ve interskalen blok için ise $1 \mathrm{mg} / \mathrm{kg}$ bupivakain ve $2 \mathrm{mg} / \mathrm{kg}$ lidokain karışımı uygulandı. Hastalara $200 \mathrm{mg}$ lidokain ve $100 \mathrm{mg}$ bupivakainden fazla ilaç uygulanmadı.

Blok işlemi yapılmadan önce ve blok uygulandıktan sonra 5. dk ve 10.dk da ölçümler kaydedildi. Duyusal blok 10. dakikada değerlendirildi. Motor bloğu değerlendirmek için Modifiye Bromage skalası kullanıldı. Blok kalitesini değer- 
lendirmek için 0.dk, (blok uygulanmadan önce) ve blok uygulandıktan sonra 5.dk, ve 10.dk.da PVI ve PI ölçümleri kaydedildi.

Uygulanan blok tipi, uygulanan ilaç miktarı, komplikasyon gelişip-gelişmediği, ASA değeri, ek hastalıklar, operasyon endikasyonu ve demografik veriler de ayrıca kayıt altına alındı.

Blok uygulandıktan 10 dakika sonra Modifiye Bromage skalası 2-3 olan ve pin-prick testinde ağrı hissetmeyen hastalar, blok başarılı kabul edilip, cerrahiye hazır kabul edildi. Ağrı hisseden hastalara $1 \mathrm{mg}$ midazolam uygulanıp $5 \mathrm{da}-$ kika daha beklendi. Eğer ağrı hissetmeye devam ediyorsa genel anesteziye geçildi. Ve bu hastalar çalışma dışı bırakıldı.

\section{istatistiksel analiz}

Çalışmada elde edilen numerik veriler aritmetik ortalama standart sapma, kategorik veriler yüzde ve frekans olarak ifade edilmiştir. İstatistiksel analizlerde SPSS Version 24 programı kullanılmıştır. Aynı dakikalarda yapılan $\mathrm{PVI}$ ve $\mathrm{PI}$ ölçümleri arasındaki ilişki spearman korelasyon testi ile ve tekrarlı ölçümler arasındaki analiz Friedman's ve post-hoc Dunn-Bonferroni testleri ile yapılmıştır. Anlamlılık düzeyi olarak $\mathrm{p}<0.05$ alınmıştır.

\section{Bulgular}

Çalışmamıza toplan otuz dört hasta dahil edildi. Bloğun başarılı olmadığı veya koopere olmayan beş hasta çalışma dışı bırakıldı. Olguların demografik özellikleri ve ölçüm yapılan değerler tabloda gösterilmiştir.(Tablo 1)

Tablo 1. Çalışmaya dahil edilen hastaların demografik özellikleri ve ölçüm değerleri

\begin{tabular}{lcccc}
\hline & Ortalama & $\begin{array}{c}\text { Standart } \\
\text { sapma }\end{array}$ & $\begin{array}{c}\text { Mini- } \\
\text { mum }\end{array}$ & $\begin{array}{c}\text { Maksi- } \\
\text { mum }\end{array}$ \\
\hline Yaş & 37,79 & 13,78 & 18 & 63 \\
Boy & 175,97 & 5,18 & 163 & 181 \\
Kilo & 77,34 & 5,73 & 58 & 84 \\
PVI 0.dk & 17,48 & 5,93 & 10 & 37 \\
PVI 5.dk & 14,62 & 4,66 & 5 & 23 \\
PVI 10.dk & 11,86 & 3,94 & 5 & 21 \\
PVI fark & 5,69 & 4,87 & 1 & 20 \\
PI 0.dk & 3,21 & 5,54 & 0,4 & 31 \\
PI 5.dk & 5,64 & 3,29 & 0,5 & 12,0 \\
PI 10.dk & 6,77 & 2,80 & 2,4 & 14,0 \\
PI fark & 4,88 & 3,66 & 0.4 & 19 \\
PI yüzde fark & 288,45 & 313,86 & 16 & 1200 \\
PVlyüzdefark & 30,14 & 18,65 & 5 & 66 \\
\hline PI, Pefüzyon
\end{tabular}

Pl; Perfüzyon indeksi, PVI; Pleth variabilite indeksi

Hastalara uygulanan blok tipine göre PVI değişimlerini değerlendirdiğimizde blok tipine göre PVI değişiminde anlamlı fark olmadığı görüldü. $(p>0,05)$

Hastalara uygulanan blok tipine göre PI değişimlerini değerlendirdiğimizde blok tipine göre PI değişiminde anlamlı fark olmadığı görüldü. ( $p>0,05)$

Hastaların ölçümleri sırasındaki PVI ile PI değerleri arasındaki korelasyon araştırılmış olup, PVI ile PI arasında anlamlı korelasyon bulunamamıştır. ( $p>0,05)$ (Tablo 2)
Tablo 2. PVI ve PI değişimi

\begin{tabular}{lcc}
\hline & $\mathbf{r}$ & $\mathbf{p}$ \\
\hline PVI 0.dk - PI 0.dk & $-0,020$ & 0,919 \\
PVI 5.dk - PI 5.dk & $-0,194$ & 0,314 \\
PVI 10.dk - PI 10.dk & $-0,351$ & 0,062 \\
PVI fark - PI fark & 0,091 & 0,640 \\
PVI yüzde-PI yüzde & $-0,183$ & 0,343 \\
\hline
\end{tabular}

PI; Perfüzyon indeksi, PVI; Pleth variabilite indeksi

Blok yapılan koldaki 0, 5 ve 10. dakikada ölçülen PVI değerleri karşılaştırıldığında; 0 ile 5 . dk, 5. dk ile 10. dk ve 0 ile 10.dk arasındaki farklılık istatistiksel olarak anlamlı bulundu. PI değerleri 0 ve $5 . d k, 5$ ve $10 . d k, 0$ ve $10 . d k$ olarak karşılaştırıldığında değişimler istatistiksel olarak anlamlı bulundu. $(p<0.05)$

Hastaların anatomisi ve geçirecekleri cerrahiye göre blok tipi belirlendi. Yapılan ileti bloklarının dağılımı Tablo 3'te gösterildi.

Tablo 3. Blok Tipleri Dağılımı

\begin{tabular}{lcc}
\hline Blok tipi & Frekans & $\%$ \\
\hline Axiller & 19 & 65,5 \\
Infraklavikular & 7 & 24,1 \\
Supraklavikular & 3 & 10,3 \\
\hline
\end{tabular}

Elde kesi, ön kolda kesi veya radius fraktürü gibi travma nedeniyle opere olan hasta grubu tüm hastaların $\% 72,2$ sidir. Hastaların ameliyat endikasyonları gruplarda toplanarak Tablo 4'de gösterildi.

Tablo 4. Cerrahi Endikasyonları

\begin{tabular}{lcc}
\hline & N:29 & $\%$ \\
\hline Elde kesi & 14 & 48,2 \\
Elde kitle & 4 & 13,7 \\
Karpal tünel sendromu & 1 & 3,4 \\
Radius fraktürü & 5 & 17,2 \\
Ön kolda kesi & 2 & 6,8 \\
Ön kolda kitle & 2 & 6,8 \\
Elde kontraktür & 1 & 3,4 \\
\hline
\end{tabular}

Blok uygulanan koldan ölçülen $\mathrm{SpHbg}$ ve $\mathrm{SpO}_{2}$ değerlerinin bazal, 5.dk ve 10.dk ölçümleri arasında anlamlı farklılık bulunmadı. $(p>0,05)$ 0.dk, 5.dk ve 10. dk ölçümleri arasında hem $\mathrm{SpHbg}$ hem de $\mathrm{SpO}_{2}$ için korelasyon saptanmadı. $(p>0,05)$ Blok uygulanmayan koldan ölçülen $\mathrm{SpO}_{2}$ monitörizasyonu ile blok uygulanan koldan ölçülen $\mathrm{SpO}_{2}$ ölçümleri arasında farklılık saptanmadı. $(p>0,05)$

\section{Tartışma}

Günümüzde rejyonal anestezi ve analjezi teknikleri, birçok avantajı nedeniyle genel anesteziye göre daha güvenilir olarak kabul edilmektedir (7). Trakeal entübasyonun gerekli olmaması, havayolu reflekslerinin korunması, analjezik ve antiemetik tüketiminin az olması, hemodinaminin stabil sürdürülmesi, uyanma ve ekstübasyon için süre gerektirmemesi, derlenme odası-anestezi sonrası bakım ünitesi-hastanede kalış sürelerinin kısa olması, intraoperatif kas gevşemesi sağlaması, intraoperatif ve postoperatif analjezi sağlaması, sempatik blokaj ile ekstremitede kan 
akımının artması ve postoperatif yara iyileşmesine olumlu katkısı rejyonal anestezinin genel anesteziye oranla belirgin üstünlükleri olarak kabul edilmektedir (8).

İleri yaştaki hastaların sahip olduğu komorbid hastalıklar nedeniyle genel anesteziye alternatif olarak rejyonal anestezi ön plana çıkmaktadır (9).

Günümüzde blok başarısını değerlendirmede pin-prick testi, sıcaklık artışı değerlendirmesi, motor fonksiyonun değerlendirilmesi veya hastanın ağı tanımlayıp-tanımlamaması gibi yöntemler kullanılmaktadır. Ama bu yöntemler hastaya bağımlı ve bazen subjektif olabilmektedir. Bu noktada blok başarısını değerlendirmede PI ve PVI gibi sayısal değerler ile objektif ölçümler önem kazanmaktadır. Blok başarısını daha objektif şekilde değerlendirebilmek anestezi hekimlerine gereksiz opiad ilaç uygulanmaması ve gereksiz genel anestezi uygulanmaması sağlar. Bu sayede de hem ameliyat süreleri gereksiz yere uzamayacak hem de ek maliyetler oluşmayacaktır.

Abdelnasser ve ark. supraklavikular bloğun başarısını değerlendirmede pulseoksimetre PI ölçümünün çalışmamızda da olduğu gibi yararlı bir araç olduğunu göstermişlerdir(10).

Ginosar ve ark. epidural anestezi sonrası yapılan PI ölçümlerinde; sempatik blokaj sonucu PI değerlerinin arttığını ve PI ölçümünün cilt sıcaklığı değişimine göre daha erken değiştiğini göstermişlerdir(11).

Galvin ve ark. epidural anestezi uygulanan hastalarda sempatektomiyi değerlendirdikleri çalışmalarında; sempatik blokaja bağlı olarak gelişen vazodilatasyon ve artmış kan akımını PI’nin başarılı şekilde yansıttığını göstermişler$\operatorname{dir}(12)$.

Klodell ve ark. hiperhidrozis nedeniyle sempatektomi yapılan 10 hastada PI' ini başarılı torasik sempatektomiyi değerlendirmek için kullanmışlardır(13). Bu çalışmada başarılı sempatektomiyi ipsilateral koldan ölçülen PI değerinde 2 kat artış olması ile tanımlamışlardır. PI'deki artışın sempatik blokaj sonucu gelişen vazodilatasyonun göstergesi olduğunu belirtmişlerdir.

Sebastiani ve ark. interskalen sinir blokajı yapılan hastalarda PI değişimini ölçmüşler; blok sonrası vazomotor tonus kaybı ve başarılı sempatik blokajı göstermede perfüzyon indeksinin hassas bir parametre olduğunu göstermişlerdir(14). Ayrıca iv sıvı bolusu uygulanması ile PVI değerlerinde blok uygulanmayan kolda, bloke kola göre daha fazla değişim olduğunu göstermişlerdir.

Takeyama ve ark. genel anestezi uygulamasında cilt insizyonunun PVI' e etkisini araştırdıkları çalışmalarında PI ve PVI değişimleri arasında negatif korelasyon olduğunu göstermişlerdir(15).

Bergek ve ark. brakial pleksus bloğu uygulanan hastalarda PVI, PI ve hemoglobin değerlerini ölçtüğü çalışmasında blok uygulanan kolda PVI değerinin azaldığı ve blok uygulanmayan kola göre daha düşük ölçüldüğü gösterilmiştir(5). Ve PI değerinin bloke kolda bazal değere göre \%188 arttığı gösterilmiştir. Bloke olmayan kolda ise PI değerinde anlamlı bir değişiklik olmamıştır. PI değerindeki bu artışın ileti bloğu sonrası gelişen vazodilatasyona bağlı olduğu gösterilmiştir. PVI değerindeki azalmanın ise yine sempatik blokaja bağlı olarak değiştiği gösterilmiştir. Bu çalışma özellikle göstermiştir ki sempatik tonus değişimi Radical-7 pulse CO-oksimetre ölçümünü güçlü şekilde etkilemekte$\operatorname{dir}(16)$.

Yin ve Ho sıvı yanıtlılığını PVI ile değerlendirdikleri çalışmalarında özellikle mekanik ventilatöre bağlı hastalarda sıvı yanıtıılığını göstermede $\mathrm{PVI}$ ' in makul düzeyde bir belirteç olduğunu ve santral venöz basınç (SVB) ölçümünden daha iyi olduğunu göstermişlerdir(4). Aynı çalışmada spontan soluyan hastalar için daha çok çalışmaya ihtiyaç olduğuna vurgu yapmışlardır.

Karahan ve ark. çalışmasında spontan solunumu olan gönüllülerde PVI, PI ve noninvaziv sürekli kardiyak output ölçümünün pozisyona göre değişimini araştırmışlar ve farklılık olmadığını ortaya koymuşlardır(17). Ayrıca PVI değerlerinin spontan soluyan hastalarda solunumsal değişimlerden etkilenebileceğine vurgu yapmışlardır. Karahan ve arkadaşları çalışmalarında hastalara supin, 20 derece Trendelenburg ve 20 derece ters Trendelenburg gibi pozisyonlar vermişler ve farklılık saptanmamıştır. Bu bilgiye dayanarak çalışmamızda blok yapılırken kola verdiğimiz hiperabdüksiyon gibi pozisyonların ölçüm değerlerini etkilemediğini ve çalışmamız için kısıtlııı oluşturmadığını söyleyebiliriz. Dolayısıyla literatürde de çalışmamızda olduğu gibi spontan soluyan hastalarda PI ve PVI' inin kullanıldığı görülmektedir.

Kart ve ark. ultrasonografi eşliğinde interskalen blok yapılan 50 hastanın hemodinamik parametrelerini inceledikleri çalışmalarında; PI’nin blok başarısını tahmin etmek için kolay uygulanabilir ve invaziv olmayan bir teknik olduğunu göstermişlerdir(18).

Kus ve ark. brakial pleksus bloğunun etkisini tespit etmek için PI’ni kullandıkları çalışmalarında; PI'nin üst ekstremite bölgesel anestezisinin başarısını hızlı bir şekilde değerlendirmek için oldukça değerli bir araç sayılabileceği sonucuna varmışlardır(19).

Pavithra ve ark. PI'nin sağlıklı bireylerde klinik kullanımını araştırdıkları çalışmalarında; PI değerlerinin ağıı ve anestezinin değerlendirilmesinde oldukça bilgi verici olduğunu göstermişlerdir(20).

Bereket ve ark. infraklavikular blok uygulanan 40 hastada, bloğun değerlendirilmesi için PI ve ultrasonografi kullandıkları çalışmalarında; PI'nin rejyonal blok başarısının erken ve objektif şekilde değerlendirilmesinde daha efektif katkı sağladığını göstermişlerdir(21). Aynı çalışmada, başarısız bloktan oluşan bir kontrol grubunun bulunmaması çalışmanın kısıtlı olduğu yön olarak belirtilmiştir. Bizim çalışmamızda da bu durum çalışmamızın kısıtlı olduğu tarafıdır. Çalışmamı uyanık hastalarda PI ve PVI parametrelerinin, rejyonal anesteziye bağlı sempatik blokajın gösterilmesinde, literatürde bu iki parametrenin beraber değerlendirildiği ilk çalışmadır. PI ve PVI değerleri blok uygulanan kolda ters yönde değişmektedir. PI değeri blok uygulanma- 
sıyla beraber artmaktayken PVI değerlerinin düştüğü görülmüştür. Fakat aralarında istatistiksel olarak anlamlı korelasyon bulunmamıştır. Çalışmamızda 0.dk, 5.dk ve $10 . \mathrm{dk}$ ölçümleri araştırma amacıyla kullanılmıştır. Belki de daha uzun süreli ölçümlerle istatistiksel olarak anlamlı sonuçlar alınabilir. Yine PVI değerlerinden yararlanarak hastaların intravasküler volüm durumu hakkında da yorum yapılabilir. Çalışmamızda PVI bazal değerlerinin en az \%10 olduğu ve ortalama değerin \%17.48 \pm 5.93 olduğu görülmüştür. Çoğu çalışmada PVI için eşik değerin \%10 ve \%19 değerleri arasında olduğu görülmüştür.

Chu ve ark. çalışmasında; 80 hastadan oluşan ve genel anestezi uygulanmış hastalarda, ameliyattan sonra postoperatif bakım ünitelerinde, ağrı takibinde $\mathrm{PI}^{\prime}$ ini kullanmış ve hastaların ağı hissetmeye başlaması ile PI değerlerinin sempatik yanıtla birlikte düştüğünü göstermiştir(22). Literatürde sempatik blokajın Pl'e etkisinin araştırıldığı daha fazla çalışma olsa da sempatik yanıt ile PI'nin azaldığını gösteren az sayıda çalışma mevcuttur. Waghalkar ve Akude'nin 60 hastadan oluşan ve endotrakeal entübasyon esnasındaki sempatik yanıtı PI ile gösterdikleri çalışmaları bunlardan biridir(23). Çalışmalarında entübasyon sırasındaki sempatik yanıtı göstermede PI'nin, kalp hızı ve kan basıncına göre daha sensitif ve daha spesifik olduğunu göstermişlerdir.

Mohamed ve ark. genel anestezi altında spinal cerrahi geçirmiş 82 hastayı içeren çalışmalarında postoperatif ağrının değerlendirilmesinde PI'ni kullanmışlardır(24). Ameliyat sonrası ağrı yönetiminde yararlanılabileceğini göstermişlerdir. Benzer bir diğer çalışmada, Hager ve ark. sağlıklı gönüllülerde ağrı hissedilmesi ile PI'nin ilişkisini göstermiştir(25). PI'nin sempatik sistem ile hem negatif hem de pozitif yönde ilişkili olduğunu gösteren bu çalışmaların varlığı ile bu belirtece olan güven artmakta ve gelecekte belki yoğun bakım, ameliyathane gibi alanlar dışında da kullanabileceği düşünülmektedir. Ayrıca ağrı yönetiminde objektif sonuçlar vermesiyle gelecekte demans, kognitif bozuklukluğu olan hastalar ve bebekler gibi ağrı hissetse de tanımlayamayan hastalarda yol gösterici olabilir.

Hasanin ve ark. sedasyon altındaki 87 yoğun bakım hastasından oluşan çalışmalarında; hastaların ağrı takibinde PI ve Davranışsal ağrı skalasını kullanmışlardır(26). Ağrı ile oluşan sempatik yanıtın PI değerini azalttığını göstermişlerdir. Ayrıca ağrılı uyarana yanıt olarak değişen Davranışsal ağrı skalası değerleri ve PI değerleri arasında korelasyon olduğunu bildirmişlerdir.

Kupeli ve Külhan vajinal doğum yapan 30 hastada ağrıyı değerlendirmede PI'nin objektifliğini değerlendirmişler$\operatorname{dir}(27)$. Bu çalışmada PI değerinin epidural analjezi uygulanmasıyla beraber arttığını ve hasta ağrı hissetmeye başlamasıyla belirgin şekilde azaldığını göstermişlerdir. Ve ağrı değerlendirilmesinde PI'nin bağımsız ve objektif bir parametre olabileceğini belirtmişlerdir.

\section{Sonuç}

Blok başarısını değerlendirmede genelde subjektif yöntemler kullanılmaktadır. Bu noktada PI ve PVI gibi sayısal değerler ve objektif ölçümler önem kazanmaktadır. Bu sayede de hem ameliyat süreleri uzamayacak hem de ek maliyetler oluşmayacaktır. Brakial pleksus bloğu uygulanan uyanık hastalarda bloğu değerlendirmek için PVI ve Pl'i kullandığımız çalışmamızda PI ve PVI değerindeki değişimlerin anlamı olduğunu gördük. PVI değeri azalsa da aralarında istatistiksel olarak anlamlı bir ilişki olmadığı görüldü. Aralarındaki muhtemel korelasyonu göstermek için daha çok çalışmaya ve daha uzun süreli ölçümlere ihtiyaç vardır. PVI ile PI belirteçlerinin kullanılmasını sınırlayan en önemli etkenler ölçüm cihazlarının ve teknolojilerinin kısmen yeni ve pahalı olmasıdır.

Etik onam: Çalışma öncesi Dicle Üniversitesi Tıp Fakültesi Girişimsel Olmayan Klinik Araştırmalar Etik Kurulundan onay alındı. (Onam no: 07, Onam tarihi: 14.11.2019).

\section{Yazar Katkıları:}

Konsept: E.Ç

Literatür Tarama: E.Ç

Tasarım: E.C

Veri toplama: E.Ç

Analiz ve yorum: G.Ö.K

Makale yazımı: E.Ç

Eleştirel incelenmesi: G.Ö.K

Çıkar Çatışması: Herhangi bir çıkar çatışmamı bulunmamaktadir.

Finansal Destek: Araştırma kapsamında herhangi bir kurum ya da kuruluştan finansal destek sağlanmamıştır.

\section{Kaynaklar}

1. Graybeal JM, Petterson M, Novak J. Correlation of peripheral perfusion index with site to site delays in detection of desaturations. Anesthesiology 2002;96:595.

2. Tsuchiya $M$, Yamada $T$, Asada A. Pleth variability index predicts hypotension during anesthesia induction. Acta Anaesthesiol Scand 2010;54:596-602.

3. Keller G, Cassar E, Desebbe O, Lehot JJ, Canesson M. Ability of pleth variability index to detect hemodynamic changes induced by passive leg raising in spontaneously breathing volunteers. Critical Care [online] 2008;12:R37. URL:https://www.ccforum.biomedcentral.com/articles/10.1186/cc6822

4. Yin JY, Ho KM. Use of plethysmographic variability index derived from the Masimo pulse oximeter to predict fluid or preload responsiveness: a systematic review and meta-analysis. Anaesthesia 2012;67:777-83.

5. Bergek C, Zdolsek JH, Hahn RG. Non-invasive blood haemoglobin and plethysmographic variability index during brachial plexus block. Br J Anaesth 2015;114:812-17.

6. Cannesson $M$, Desebbe $O$, Rosamel $P$, ve ark. Plethvariability index to monitor the respiratory variations in the pulse oximeter plethysmographic waveform amplitude and predict fluid responsiveness in the operating theatre. Br J Anaesth 2008;101:200-6.

7. D'Alessio JG, Rosenblum M, Shea KP, Freitas DG. A retrospective comparison of interscalene block and general anesthesia for ambulatory surgery shoulder arthroscopy. 
Regional Anesthesia and Pain Medicine 1995;20:62-68.

8. Mirza F, Brown AR. Ultrasound-Guided Regional Anesthesia for Procedures of the Upper Extremity. Anesthesiology Research and Practice [online] 2011;2011:579824. URL:http://www.europepmc.org/article/PMC/3119462

9. Tsui $B$, Wagner A, Finucane B. Regional Anaesthesia in the Elderly, A Clinical Guide. Drugs Aging 2004;21:895-910.

10. Abdelnasser A, Abdelhamid B, Elsonbaty A, Hasanin A, Rady A. Predicting successful supraclavicular brachial plexus block using pulseoximeter perfusion index. $\mathrm{Br} J$ Anaesth 2017;119:276-80.

11. Ginosar $Y$, Weiniger $C F$, Meroz $Y$, ve ark. Pulseoximeter perfusion index as an early indicator of sympathectomy after epidural anesthesia. Acta Anaesthesiol Scand 2009;53:10118-26.

12. Galvin EM, Niehof S, Verbrugge SJ, ve ark. Peripheral flow index is a reliable and early indicator of regional block success. Anesth Analg 2006;103:239-43.

13. Klodell CT, Lobato EB, Willert JL, Gravenstein N. OximetryDerived Perfusion Index for Intraoperative Identification of Successful Thoracic Sympathectomy. Ann Thorac Surg 2005; 80:467-70.

14. Sebastiani A, Philippi L, Boehme S, ve ark. Perfusion index and plethysmographic variability index in patients with interscalene nevre catheters. Can J Anesth 2012;59:10951101.

15. Takeyama M, Matsunaga A, Kakihana $Y$, Masuda M, Kuniyoshi T, Kanamara Y. Impact of skin incision on the pleth variability index. J Clin Monit Comput 2011;25:215-21.

16. Iskandar $\mathrm{H}$, Wakim N, BenardA, ve ark. The effects of in terscalene brachial plexus block on humeral arterial blood flow: a Doppler ultrasound study. Anesth Analg 2005;101:279-81.

17. Karahan MA, Atlas A, Pehlivan VF, ve ark. Spontan Solunumu Olan Gönüllülerde Cerrahi Hasta Pozisyonlarının Plet Değişkenlik Indeksi , Perfüzyon İndeksi ve Noninvaziv Sürekli Kardiyak Output Ölçüm Yöntemi Üzerine Olan Etkisi. Harran Üniversitesi Tıp Fakültesi Dergisi. 2020;17:98103.

18. Kart CE, İsbir AC, Avcı O, Kol Öi, Kaygusuz K, Gürsoy S. The Effects of Interscalene Block Performed Alone or with Ultrasonography-Guided Peripheric Nerve Stimulator on Block Success, Hemodynamic Parameters and Perfusion Index. Turkiye Klinikleri J Cardiovasc Sci 2020;32:37-44.

19. Kus $A$, Gürkan $Y$, Görmüş SK, Solak M, Toker K. Usefulness of perfusion index to detect the effect of brachial plexus block. J Clin Monit Comput 2013;325-28.

20. Pavithra SM, Swetha J, Shruthi RS. Clinical Usage of Peripheral Perfusion Index in Individuals with Pain - A Preliminary Study. IJRASET 2018;6:1535-40.

21. Bereket MM, Aydın BG, Küçükosman $G$ ve ark. Perfusion Index and ultrasonography in the evaluation of infraclavicular block. Minerva Anestesiol 2019;85:746-55.

22. Chu CL, Huang YY, Chen YH, Lai LP, Yeh HM. An observational study: The utility of perfusion index as a discharge criterion for pain assessment in the postanesthesia care unit. PLoS ONE 2018;13:e0197630.

23. Waghalkar $P$ and Akude N. Comparison of perfusion index (PI) with other non-invasive hemodynamic monitors of stres response following endotracheal intubation. International Journal of Biomedical Research 2016;7:490-494.
24. Mohamed SAR, Mohamed NN, Rashwan D. Pulse co-oximetry perfusion index as a tool for acute postoperative pain assessment and its correlation to visual analogue pain score. Research and Opinion in Anesthesia\& IntensiveCare 2015;2:62-67.

25. Hagar H, Church S, Mandadi G, Pulley D, Kurz A. The perfusion index as measured by a pulse oximeter indicates pain stimuli in anesthetized volunteers. Anesthesiology 2004;101:A514.

26. Hasanin A, Mohamed SAR, El-adawy A. Evaluation of perfusion index as a tool for pain assessment in critically ill patients. J Clin Monit Comput 2017;31:961-965.

27. Kupeli I, Kulhan NG. Can Perfusion Index be used as an Objective Tool for Pain Assessment in Labor Analgesia Pak J Med Sci. 2018;34:1262-1266. 